\title{
Facilitating socio-pleasure as mediated by ubiquitous technology
}

\author{
Marije Kanis, Willem-Paul Brinkman, Robert Macredie \\ Brunel University \\ Uxbridge, Middlesex UB8 3PH \\ United Kingdom \\ marije.kanis@brunel.ac.uk,willem.brinkman@brunel.ac.uk, robert.macredie@brunel.ac.uk
}

\begin{abstract}
This paper aims to increase understanding of how ubiquitous interactive systems could facilitate SocioPleasure: the enjoyment derived from relationships with others. A framework, termed THE Medium model, is presented; it describes the factors that could affect socio-pleasure and it is used to classify and design technologies.
\end{abstract}

Keywords

Social interaction, ubiquitous technology, sociopleasure, THE Medium model, positivism

\section{INTRODUCTION}

Evolutionary development of useful technology is accelerated when developers have an understanding of human needs (Shneiderman, 2002). Mumford (1934) characterized the goal of technology as serving human desires. As reflected in Maslow's hierarchy of needs, and as further demonstrated and evaluated in empirical studies, is that humans have a basic need of contact with others (Baumeister \& Leary, 1995). People seek and require supportive relationships for their health and well-being. However, some believe that current technologies do not always support this need very well. For example, research suggests that the use of computers and the Internet may contribute to social isolation and individual stress levels (Kraut et al., 2002) and technology exhibits shortcomings when compared to face-to-face interaction (Markus, 1994). Conversely, sociability might become equally important as usability if emerging technologies offer the potential to catalyze joyful, social interactions. Primarily, this is because the expanding context in which technology is used, affords new opportunities for interacting with computers or, better still, people. However, we have to understand how to capitalize and use technology for socio-pleasurable purposes. In particular, the ways ubiquitous technologies could facilitate fun and positive, social interactive experiences and how these might improve or change the nature of social mediated interaction need to be investigated. THE Medium model is proposed as a starting point for addressing these issues.

\section{THE Medium Model for Socio-Pleasure}

Studies from CSCW, social and positive psychology, and in particular theories of on-line communities, have identified factors that impact on social well-being and bonding (e.g., Hogg \& Vaughan, 2005; Preece, 2000). After reviewing these in depth, four key categories emerged from the literature: Time; Human; Environment; and Medium. These formed the basis of THE Medium model encompassing factors that could affect socio-pleasurable interaction.

Table 1: THE Medium model \& factors likely to affect socio-pleasure

\begin{tabular}{|c|c|}
\hline Category & Factors that could affect socio-pleasure \\
\hline \multirow{5}{*}{ TIME } & Duration of interaction(s) \\
\hline & History of interactions \\
\hline & Synchronous/ Asynchronous (e.g., iChat/eMail) \\
\hline & Zeitgeist \\
\hline & Positive moment in time (e.g., birthday) \\
\hline \multirow{16}{*}{ HUMAN } & Personal characteristics \\
\hline & (e.g., Age, Gender, Personality, Physical attractiveness) \\
\hline & Physical contact \& expression \\
\hline & Trust \& Security (e.g., self- disclosure) \\
\hline & Face-to-Face interaction (visibility) \\
\hline & Person's cognitive state (e.g., attention) \\
\hline & Person's Physical state (e.g., under exertion) \\
\hline & Shared activity (e.g., play) \\
\hline & Similarity (e.g., shared beliefs, interests) \\
\hline & Reciprocity \\
\hline & Person's cognitive state (e.g., attention) \\
\hline & Person's mental state (e.g., persons' emotions) \\
\hline & Negative/Positive emotion toward other(s) \\
\hline & Familiarity \\
\hline & Availability \\
\hline & Expectation of interaction \\
\hline \multirow{6}{*}{ ENVIRONMENT } & Proximity (distance) \\
\hline & Place \& space \\
\hline & Presence/Propinquity (=nearness in place) \\
\hline & Culture \\
\hline & Weather conditions \\
\hline & Neg./ Pos. environmental impression \\
\hline \multirow{6}{*}{\begin{tabular}{|l} 
MEDIUM \\
[No Technology \\
Desktop technology \\
Mobile Technology \\
Augmented reality \\
Ubiquitous Technology]
\end{tabular}} & $\begin{array}{l}\text { Medium's characteristics } \\
\text { (e.q. content, structure, behaviour, aesthetics) }\end{array}$ \\
\hline & Medium's perceived benefits \\
\hline & embeds a motivational force \\
\hline & embeds a 'socially transforming interface' \\
\hline & embeds an escape mechanism \\
\hline & is unusual, a novelty \\
\hline
\end{tabular}

THE Medium model as a design and analytical tool Although, not in control of every factor (e.g., zeitgeist, personal characteristics), this model shows that developers have a wide spectrum of factors to consider when designing for socio-pleasure. These factors differ 
in importance at various social stages and in differing contexts (e.g., increasing social awareness, breaking the ice, community building and maintaining relationships). Also, this model does not necessarily show that ubiquitous technologies can facilitate better socio-pleasurable interactions than other technologies, but shows that ubiquitous technologies have characteristics such as flexibility in time, human visibility and environment that could be capitalized on. To help build an understanding of this model and analyse current interactive experiences, illustrations and examples that aim to encourage socio-pleasurable interaction are explored below.

Time: In the model, time and its factors, including the duration of interaction(s) are seen as influential in the design of socio-pleasurable interactions. Agamanolis (2003) describes the Palimpsest project, an interactive experience that overcomes time as an obstacle of social presence. It superimposes layers of recorded social interaction and presents them as a single image and so facilitates chance encounters between different points in time.

Human: Similarity in interests and beliefs has been identified by the model as an important factor when establishing human relationships. For example, Lovegetty was designed to match people with similar interests. Shared activity -in the form of a soccer game over distance- is used by Breakout for Two, demonstrating physical exertion as a factor in social bonding. iBand (Kanis et al.,2005), a technology enhanced bracelet, is a ubiquitous social networking tool that uses face-to-face interaction and physical contact and expression in the form of a handshake as a way to break the ice.

Environment: This category is bridged by the proximity factor that permits Human's familiarity, availability and expectation of continued interaction to come into play in determining social attraction. Attempts in this category, such as video- conferencing applications aim to bridge distances and enable encounters between people in different places. Talkman for the Portable Sony Playstation incorporates the culture factor as it is designed to be a fun 'ice-breaking' translator.

Medium: The medium is basically everything that conveys information and this is the form in which all the factors are framed and come together. Developers can control usability, but they cannot control sociability (Preece, 2000). However, in the way they design the medium (as in technical application) they can frame the interactions and influence the sociopleasurable experience.

\section{Postivity}

Postivity is a ubiquitous system under development that uses THE Medium model as a design tool. One important factor it accounts for is that human's positive emotions can lead to social bonds (Fredrickson, 2003). Postivity provides every person with the ability to act as a 'broadcast station' to deliver their positive thoughts, emotions and impressions to people in close proximity. The system will provide fixed prefixes such as: "Today I like..." and "This is nice about you:..." that people need to complete, encouraging social positivism. For the system's prefixes and further mechanisms, Human's reciprocity principle (we tend to like those who like us) is taken into consideration. Positive postings will be broadcasted between people that pass in near proximity so that they accumulate positive (re) collections from their 'ubiquitous' neighbours. In this way, the sense of belonging (to a possibly new 'Postivity community') is being explored. Additionally, users' revelations could potentially serve as icebreakers between people or increase social awareness. Other factors of THE Medium model will be investigated as the design of the Postivity system unfolds.

\section{CONCLUSION}

We have presented THE Medium model as a framework for designing socio-pleasurable interactions. Immediate future work will involve prototype implementation and empirically evaluation to refine the model, leading to robust design principles for supporting socio-pleasurable interactions through ubiquitous technology.

\section{REFERENCES}

Agamanolis, S. (2003). Designing Displays for Human Connectedness In K. O'Hara, M. Perry, E. Churchill \& D. Russell (Eds.), Public and Situated Displays: Social and interactional aspects of shared display technologies: Kluwer.

Baumeister, R. F., \& Leary, M. R. (1995). The need to belong: Desire for interpersonal attachments as a fundamental human motivation. Psychological Bulletin (117), 497-529.

Fredrickson, B. L. (2003). The value of positive emotions. American Scientist (91), 330-333.

Hogg, M. A., \& Vaughan, G. M. (2005). Social Psychology (4th edition). London: Prentice Hall.

Kanis, M., Winters, N., Agamanolis, S., Gavin, A., \& Cullinan, C. (2005). Toward wearable social networking with iBand. Paper presented at the CHI '05 Extended Abstracts on Human Factors in Computing Systems Portland, USA.

Kraut, R., Kiesler, S., Boneva, B., Cummings, J., Helgeson, V., \& Crawford, A. (2002). Internet Paradox Revisited. Journal of Social Issues 58(1), 49-74.

Markus, M. L. (1994). Finding a happy medium: explaining the negative effects of electronic communication on social life at work. ACM Transactions on Information Systems (TOIS), 12(2), 119-149.

Mumford, L. (1934). Technics and civilization. New York: Harcourt.

Preece, J. (2000). Online Communities: Designing Usability, Supporting Sociability. Chichester: John Wiley \& Sons.

Shneiderman, B. (2002). Leonardo's laptop: human needs and the new computing technologies. Cambridge, Massachusetts: MIT Press. 